\title{
Immunotherapy by targeting of VGKC complex for seizure control and prevention of cognitive impairment in a mouse model of epilepsy
}

\author{
ZHILIANG FAN $^{1 *}$, XIAOJUAN FENG ${ }^{2 *}$, ZHIGANG FAN $^{3}$, XINGYUAN ZHU $^{1}$ and SHAOHUA YIN ${ }^{1}$ \\ ${ }^{1}$ The Third Department of Neurology; Departments of ${ }^{2}$ Ultrasound and ${ }^{3}$ Respiration, \\ Xingtai People's Hospital of Hebei Province, Xingtai, Hebei 054001, P.R. China
}

Received July 29, 2017; Accepted April 16, 2018

DOI: $10.3892 / \mathrm{mmr} .2018 .9004$

\begin{abstract}
Epilepsy is a type of refractory neurologic disorder mental disease, which is associated with cognitive impairments and memory dysfunction. However, the potential mechanisms of epilepsy are not well understood. Previous evidence has identified the voltage gated potassium channel complex (VGKC) as a target in various cohorts of patients with epilepsy. In the present study, the efficacy of an antibody against VGKC (anti-VGKC) for the treatment of epilepsy in mice was investigated. A mouse model of lithium-pilocarpine temporal lobe epilepsy was established and anti-VGKC treatment was administered for 30 days. Memory impairment, anxiety, visual attention, inhibitory control and neuronal loss were measured in the mouse model of lithium-pilocarpine temporal lobe epilepsy. The results revealed that epileptic mice treated with anti-VGKC were able to learn the task and presented attention impairment, even a tendency toward impulsivity and compulsivity. It was also exhibited that anti-VGKC treatment decreased neuronal loss in structures classically associated with attentional performance in hippocampus. Mice who received Anti-VGKC treatment had inhibited motor seizures and hippocampal damage as compared with control mice. In conclusion, these results indicated that anti-VGKC treatment may present benefits for improvements of the condition of motor attention impairment and cognitive competence, which suggests that VGKC may be a potential target for the treatment of epilepsy.
\end{abstract}

Correspondence to: Dr Shaohua Yin, The Third Department of Neurology, Xingtai People's Hospital of Hebei Province, 16 Hongxing Street, Xingtai, Hebei 054001, P.R. China

E-mail: shaohuayindoctor@163.com

${ }^{*}$ Contributed equally

Key words: epilepsy, voltage gated potassium channel complex, anti-voltage gated potassium channel complex, hippocampus, cognitive competence

\section{Introduction}

Epilepsy is a common neurological disorder disease, which affects more than 50 million populations in the developing country $(1,2)$. Though several new antiepileptic drugs have emerged over the past years, the incidence of refractory epilepsy remains high and seizure freedom eludes many patients with epilepsy (3-5). Epidemiological data has indicated that more than twenty percent of newly diagnosed patients are translating into refractory epilepsy every year (6,7). Many factors affect the treatment of epilepsy including environmental factors and genetic factors $(8,9)$. In addition, patients with refractory epilepsy present neuronal loss in hippocampus, which is a common pathogenetic condition (10). Therefore, target therapy for molecular in hippocampus may be beneficial for the treatment of patient with refractory epilepsy (11-13). Furthermore, previous reports have made endeavor to understand the potential molecular mechanism of refractory epilepsy (13-15). However, exploring more and more target drug therapies are still required for refractory epilepsy patients.

Currently, various antibodies targeting of neuronal proteins have presented therapeutic effects for epilepsy patients $(16,17)$. Voltage gated potassium channel complex (VGKC) involves in epilepsy and is associated with memory impairment, anxiety, visual attention and inhibitory control in nerve area $(18,19)$. Study has reported that VGKC complex nerve hyperexcitability and limbic encephalitis was associated with the spectrum of immunotherapy-responsive clinical features in patients with epilepsy (20). VGKC antibody-associated encephalopathy was reported and conclusion exhibited psychotic disorder cause by VGKC (21). Although substantial evidences upon recovery are investigated after immunotherapy, residual amnestic deficits is frequently occurred in patients with epilepsy (22).

Many studies have shown that VGKC antibodies directly neutralized neuronal antigens on cell surface in patients with epilepsy, suggesting Anti-VGKC is specificity for molecules in epilepsy. Some patients with epilepsy exhibited higher autoantibodies of VGKC-complex $(23,24)$. Therefore, this study investigated the efficacy of Anti-VGKC on motor attention impairment, cognitive competence, impulsivity, compulsivity and seizures in a subpopulation of neuroprotected mice. A recent study of the therapeutic effects of Anti-VGKC immunotherapy 
on cognitive improvement and neuronal loss has indicated that Anti-VGKC was beneficial for faciobrachial dystonic seizures, which contributed to motor attention impairment and potentially treatable disorder (25). However, these reports only studied benefits of VGKC-complex antibody for limbic encephalitis, but not analyzed the anxiety, visual attention and inhibitory control. Also, few preclinical studied the fundamental mechanism and therapeutic effects of Anti-VGKC on epilepsy and cognitive competence, impulsivity, compulsivity and seizures in a subpopulation of neuroprotected rats were limited to the few preceding reported (26).

In the present study, the effects of Anti-VGKC on the anticonvulsant activity of seizure control and improvements of cognitive function have been evaluated in models of epilepsy. A series of experiments were performed to analyze the therapeutic effects of Anti-VGKC for models of epilepsy mice (Fig. 1). Our data presented that cognitive impairment was relieved after immunotherapy of Anti-VGKC. In addition, although mice brain PET has shown that evidence of hippocampal atrophy was associated with progress to epilepsy observed in mice with epilepsy, the primary of hippocampal signal changes seldom reported in previous study. In this study, we undertook experiments to investigate the role of Anti-VGKC in mice model of lithium-pilocarpine temporal lobe epilepsy. Further evaluation of more preclinical data is essential to understand the potential impact of Anti-VGKC interactions on efficacy, tolerability, and dosing of new antiepileptic drug.

\section{Materials and methods}

Ethical approval and participant consent. The present study was approved by the Ethics Committee of Provincial Hospital affiliated to Shandong University (ref. 11/H1011/102). All surgery and euthanasia of experimental mice were performed under sodium pentobarbital anesthesia to make minimize suffering.

Animals. A total of $20 \mathrm{~J} 20$ mice (eight weeks old, 24-32 g body weight) were purchased from the Chinese Academy of Sciences Institute of Biophysics (Beijing, China). All mice were housed at preference temperature $\left(22-24^{\circ} \mathrm{C}\right)$ under a $12 \mathrm{~h}$ light-dark cycle and free accessed food and water. Mice were divided into two groups ( $\mathrm{n}=10$ in each group). The epileptic mice were treated with intravenous injection for 30 days of $0.24 \mathrm{mg} / \mathrm{kg}$ Anti-VGKC or vehicle of PBS once a day for a total of 30 days.

Reverse transcription-quantitative polymerase chain reaction $(R T-q P C R)$. Total RNA was obtained from peripheral blood mononuclear cells and hippocampus cells by using RNAeasy mini kit (Qiagen Sciences, Inc., Gaithersburg, MD, USA). A total of $1 \mu \mathrm{g}$ total RNA was reverse transcribed into cDNA. One-tenth of the cDNA was subjected to qPCR using an iQ SYBR-Green system. All the primers were synthesized by Invitrogen; Thermo Fisher Scientific, Inc. (Waltham, MA, USA). Primers sequences were as follow: VGKC, forward, 5'-CGCAGAACTTTCATTCTTTGGAC-3'; reverse, 5'-CTG GGCAAGTTTCAATAGGAGA-3'; Foxp2, forward, 5'-AAC AGAGACCACTGCAGGTGCC-3'; reverse, 5'-TCCCTGACG
CTGAAGGCTGAG-3'; SxIP, forward, 5'-GTGCAGTTGAGG TCCTTTCG-3'; reverse, 5'-GTCAGGAACAAACCCAGC TG-3'; EB, forward, 5'-GGTACAGGTGTGGTTCCAGA-3'; reverse, 5'-CTGGAGGGTGTCTGGAAGAG-3'; $\beta$-actin, forward, 5'-CGGAGTCAACGGATTTGGTC-3'; reverse, 5'-AGCCTTCTCCATGGTCGTGA-3'. PCR following thermocycling conditions were performed: 40 amplification cycles consisting of denaturation at $95^{\circ} \mathrm{C}$ for $5 \mathrm{~min}$, primer annealing at $55^{\circ} \mathrm{C}$ for $20 \mathrm{sec}$ with touchdown to $56^{\circ} \mathrm{C}$ for $20 \mathrm{sec}$, and applicant extension at $72^{\circ} \mathrm{C}$ for $5 \mathrm{~min}$. Relative mRNA expression changes were calculated by $2^{-\Delta \Delta C q}(27)$. The results are expressed as the n-fold way compared to $\beta$-actin.

Enzyme Linked Immunosorbent Assay (ELISA) analysis. VGKC proteins ELISA kits (cat. no. CSB-E13512h; Cusabio Biotech Co., Ltd., Houston, USA) were used to determine serum and cerebrospinal fluid concentration levels of the VGKC. The operating steps were conducted according to the manufacturer's instructions. The results were analyzed using an ELISA reader system (Bio-Rad Laboratories, Inc., Hercules, CA, USA).

Electroencephalography (EEG). All mice treatment with VGKC or PBS underwent conventional 19-channel scalp EEG examination. On day 30, experimental mice were anesthetized to during the measurement. EEG was measured starting from the recovery of movement and data were recorded continuously for 30 min using the 10-20 system (EGI, Inc., Eugene, OR, USA) according to manufacturer's instructions.

Positron emission tomography imaging (FDG-PET). FDG-PET was used to analyze the discharge sites by using statistical parametric mapping (SPM) software (SPM v2) and identified significant regions of cerebral neurons. FDG-PET images were spatially normalized onto the MNI (Montreal Neurological Institute, McGill University, Montreal, Canada) PET brain template which defined regions of interest. Normalized images were smoothed by convolution with a $10 \mathrm{~mm}$ FWHM Gaussian kernel to increase the signal to noise ratio. Detailed procedures for FDG-PET acquisition and image processing have been described in previous study (28).

Behavioral tests. On day 30, cognitive competence of mice was determined by the open field activity levels that a $60 \times 60 \times 25 \mathrm{~cm}$ black plexiglas box (length $\mathrm{x}$ width $\mathrm{x}$ height) was used to analyzed therapeutic effects of Anti-VGKC for epilepsy mice. Experimental mice were placed to the open black box $15 \mathrm{~min}$ and the behaviors were monitored and evaluated using an auto-tracking system (v3.2; SmarTrack; Smart Solutions, Inc., Madison, WI, USA). The 5-choice serial reaction time task (5-CSRTT) was used to evaluate a mice who exhibited beneficial performance according to previous study (29).

Morris water maze test. The path efficacy was analyzed using Morris water maze test at prior and post treatment of Anti-VGKC and control. Briefly, experimental mice were placed a circular stainless-steel tank with $155 \times 60 \mathrm{~cm}$ (diameter $\mathrm{x}$ depth). Tank was filled with $40 \mathrm{~cm}$ water and skim milk at $27.0 \pm 1.0^{\circ} \mathrm{C}$. Subsequently, the path efficacy in learned to find a hidden circular platform was observed in experimental mice. 


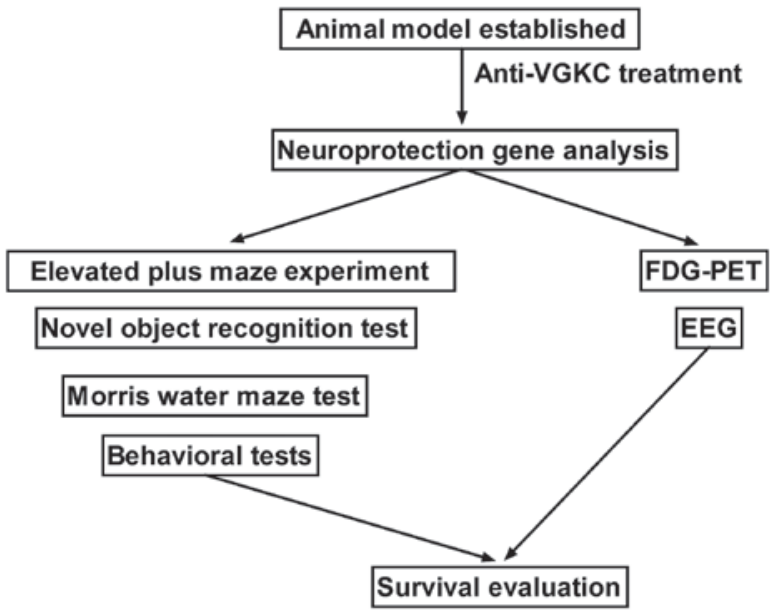

Figure 1. Schematic of the experimental procedures applied for anti-VGKC treatment in mice with epilepsy. VGKC, voltage gated potassium channel complex; FDG-PET, fluorodeoxyglucose-positron emission tomography; EEG, electroencephalography.

Novel object recognition test. The novel object recognition test was performed in a 50x50x49 cm (length $\mathrm{x}$ width $\mathrm{x}$ height) white plexiglass box prior and post treatments. On day 30 , experimental mice $(n=4)$ in Anti-VGKC and control groups were subjected to a training program that all mice were exposed to two of the same objects. We recorded the exploration time for all mice. Twenty-four hours later, mice were placed back in white plexiglass box to recognize a novel object in the same place. The times in searching the novel objects were measured and recorded for accessing the spatial cognitive ability of the mice.

Experiment of elevated plus maze. Coordinating behavior, spiking frequency and escape latency of mice were evaluated using an elevated plus maze trial based on the hypothesis that mice exhibited fear of open field. The details of the elevated plus maze trial were as described previously (30), with the space the mice were subjected to increased three times to a size of 100x20x80 (length $\mathrm{x}$ width $\mathrm{x}$ height) $\mathrm{cm}$. The experimental mice with schizophrenia were placed into the center of the elevated plus maze. The mice with schizophrenia were made to face the open arm for a total of $5 \mathrm{~min}$. The time spent in the open and closed arms was recorded and calculated by employing the formula: D2 $=(B-A) /(B+A)$. A, represented the time spent in the open arm; $\mathrm{B}$, represented the time spent in the closed arm; and D2, represented the discrimination index. Anxious behavior was measured using the aforementioned formula.

Rankin score and Status Epilepticus Severity Score (STESS). The ability of Rankin score and STESS was evaluated as described previously $(31,32)$. STESS' ability was used to predefine outcome of Anti-VGKC for mice with epilepsy. Rankin score was used to analyze the degree of nervous functional defects of epilepsy mice.

Histologic analysis. Hippocampus was isolated from experimental mice as described previously (33). Paraffin-embedded tissue sections were prepared and epitope retrieval was performed for further analysis. The paraffin sections were incubated with hydrogen peroxide $(3 \%)$ for $15 \mathrm{~min}$ at $37^{\circ} \mathrm{C}$. Tissue sections were stained with hematoxylin and eosin $(5 \%)$ for $1 \mathrm{~h}$ at $37^{\circ} \mathrm{C}$. After PBST three washes, tissue sections observed using a light microscope (Olympus BX51; Olympus Corporation, Tokyo, Japan).

Immunofluorescence. Hippocampal tissue was cut into $4 \mu \mathrm{m}$ thick sections and mounted on glass slides. The paraffinized sections were heated in an oven at $65^{\circ} \mathrm{C}$ for $24 \mathrm{~h}$, dewaxed to water and rinsed with PBS three times. The washed sections were placed in EDTA buffer (Beinuo Bioscience Inc., Shanghai, China), and then boiled at a low heat following an interval of $10 \mathrm{~min}$ at $65^{\circ} \mathrm{C}$ for a total of three intervals. Following natural cooling, the sections were washed with PBS three times, and were placed into 3\% hydrogen peroxide solution (Beina Bioscience Inc.) and washed with PBS three times. Tissue sections were incubated with rabbit anti-mouse monoclonal antibodies: Transcripts of forkhead-BOX P2 (Foxp-2) (ABE73), SxIP (ABE86) and microtubule end binding (EB) (ABC467, all 1:2,000 dilutions; all EMD Millipore; Billerica, MA, USA) at $4^{\circ} \mathrm{C}$ for $12 \mathrm{~h}$. After rinsing, sections were incubated a with DyLight488 or DyLight650-conjugated secondary antibody (1:5,000; Pierce Biotechnology; Thermo Fisher Scientific, Inc.) at $37^{\circ} \mathrm{C}$ for $2 \mathrm{~h}$. The sections were then washed with PBS and observed by fluorescent video microscopy (BZ-9,000; Keyence Corporation, Osaka, Japan).

Statistical analysis. All data were expressed as mean \pm standard deviation. All experiments were repeated at least three times. Statistical analysis was performed using GraphPad software 5.0 (GraphPad Software, Inc., La Jolla, CA, USA). Statistical differences were analyzed by using student $t$ tests or one-way analysis of variance followed by Tukey HSD test. ${ }^{*} \mathrm{P}<0.05,{ }^{*} \mathrm{P}<0.01$ were considered to indicate a statistically significant difference.

\section{Results}

In vivo therapeutic effects of Anti-VGKC in mice model of epilepsy. In order to investigate the expression of VGKC in mice model of epilepsy, we analyze the concentration level of VGKC in cerebrospinal fluid (CSF) and serum. The results in Fig. 2A and B, we showed that VGKC was up-regulated and Anti-VGKC decreased mRNA level of VGKC in peripheral blood mononuclear cells (PBMC) and serum. We demonstrated that Anti-VGKC down-regulated VGKC mRNA levels in hippocampus cells and cerebrospinal fluid (CSF) (Fig. 2C and D). Our data in Fig. 2E exhibited that Anti-VGKC presented a higher affinity with VGKC, which indicated Anti-VGKC could decrease the concentration level of VGKC in mice with epilepsy. In addition, several proteins related cognitive competences were evaluated in hippocampus cells in mice with epilepsy. The results in Fig. 2F-H showed that mRNA of Foxp-2, SxIP and EB were down-regulated in hippocampus cells in mice with epilepsy. These data suggested VGKC were up-regulated and neuroprotective gene were down-regulated in mice subjected epilepsy.

Performance of epilepsy mice after treatment with Anti-VGKC. We further analyzed the short therapeutic effects of Anti-VGKC in epilepsy mice in a four-week treatment 

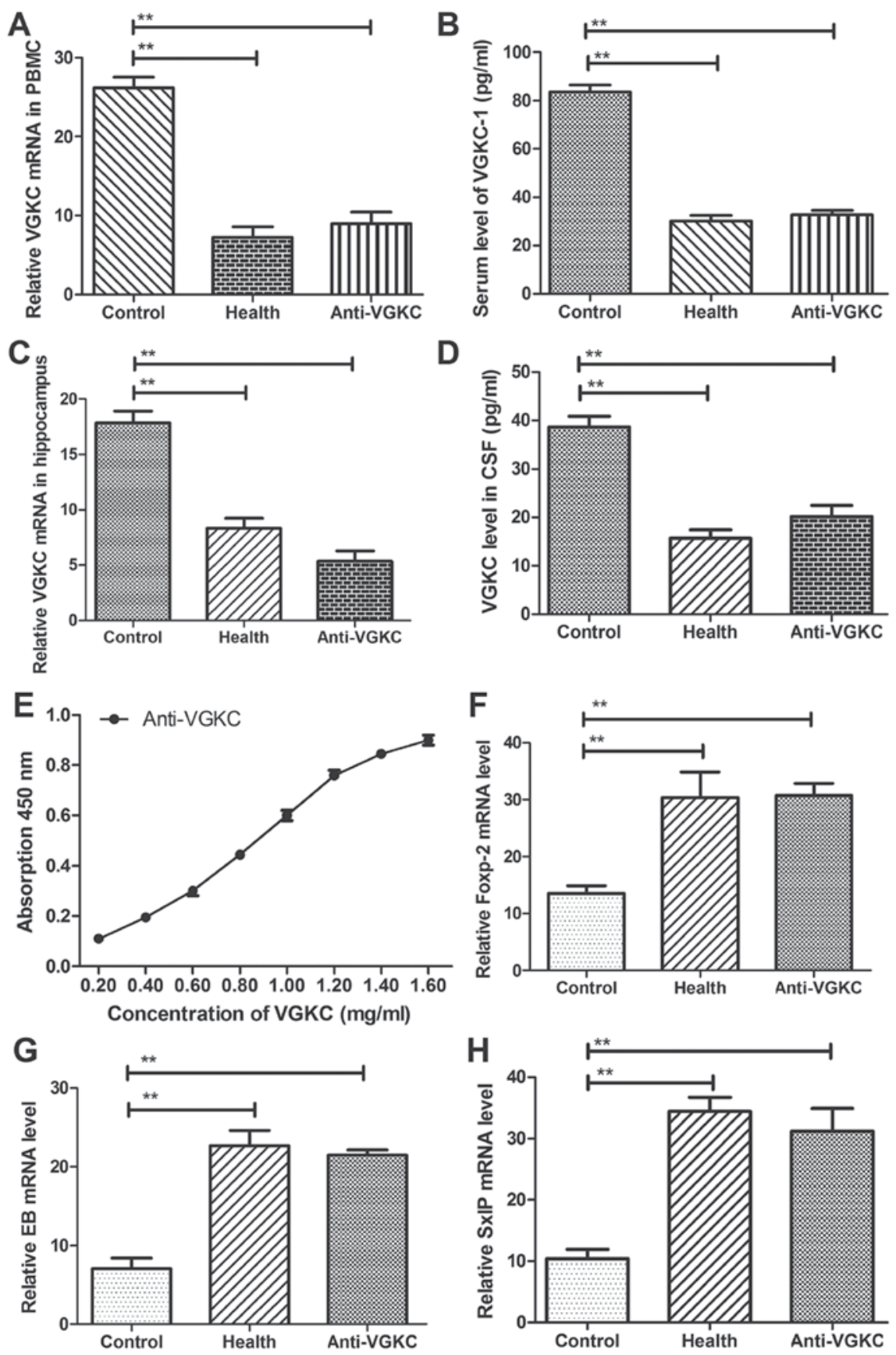

Figure 2. Expression of VGKC and the effects anti-VGKC on temporal lobe epileptiform spiking in vivo. (A) Anti-VGKC decreased mRNA levels of VGKC in PBMCs in mice with epilepsy. (B) Anti-VGKC decreased serum levels of VGKC in mice with epilepsy. (C) Relative VGKC mRNA levels in the hippocampus between the anti-VGKC and control group in mice with epilepsy. (D) VGKC levels in CSF between the anti-VGKC and control groups in mice with epilepsy. (E) The affinity of anti-VGKC with VGKC determined by ELISA. Neuroprotective gene expression of (F) Foxp-2, (G) EB and (H) SxIP in hippocampus cells in epileptic mice following treatment with anti-VGKC or control. Data are presented as the mean \pm standard deviation $\left(\mathrm{n}=5 /\right.$ group). ${ }^{* *} \mathrm{P}<0.01$, as indicated. Health group, positive control; VGKC, voltage gated potassium channel complex; PBMCs, peripheral blood mononuclear cells; CSF, cerebrospinal fluid; Foxp-2, forkhead-BOX P2; EB, microtubule end binding.

period. Our data in Fig. 3A showed that Anti-VGKC markedly decreased the spike discharge rate compared to control mice. The 5-choice serial reaction time task (5-CSRTT) was used to evaluate the mice who exhibited beneficial performance corresponding to standard testing conditions. The results in Fig. 3B showed that Anti-VGKC treatment improved behaviors of mice with epilepsy scored by STESS. As shown in Fig. 3C, Anti-VGKC treatment improved cortical spiking of EEG compared to control. We demonstrated that time-frequency (Morlet wavelets) power spectra in epilepsy mice were markedly improved by Anti-VGKC treatment (Fig. 3D). We also showed that Anti-VGKC treatment decreased the total seizure duration and increased the whole traveled distance in the open field activity test compared to control (Fig. 3E and F). These results indicate that Anti-VGKC can improve behaviors and discharge activity of epilepsy mice.

Effect of Anti-VGKC on cortical epileptiform spiking and neuronal remission in vivo in mice model of epilepsy. In order to determine whether the effects of Anti-VGKC were 
A

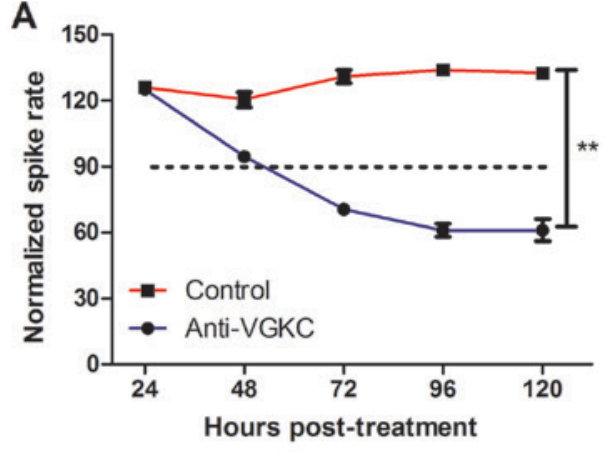

B

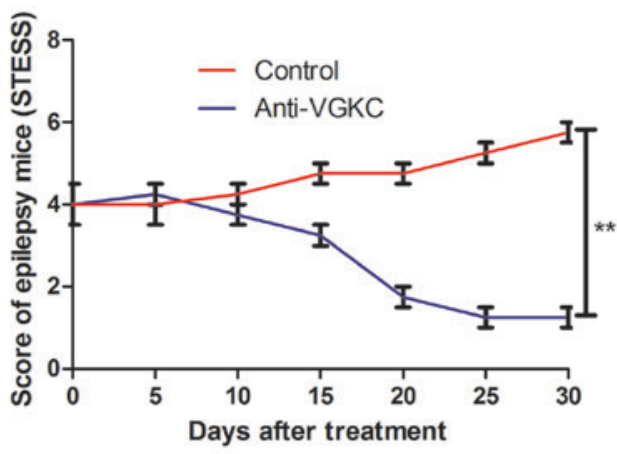

C
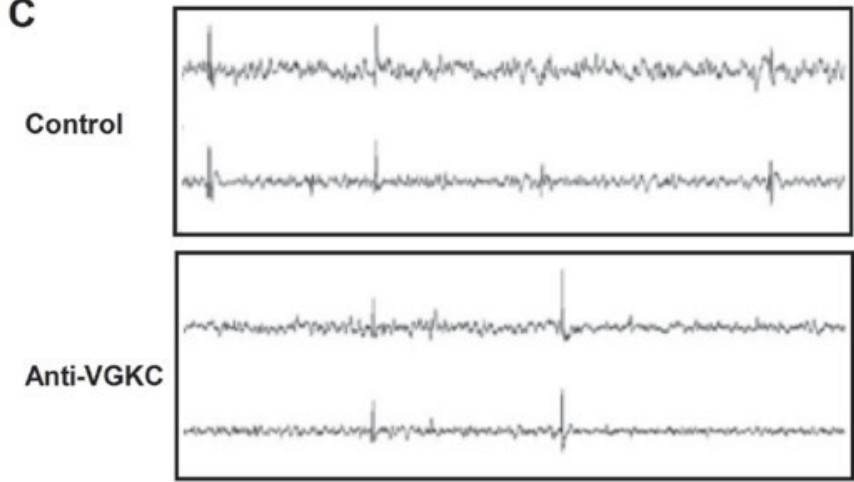

D

Control

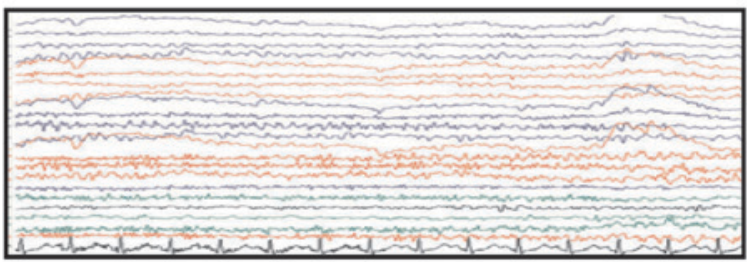

Anti-VGKC
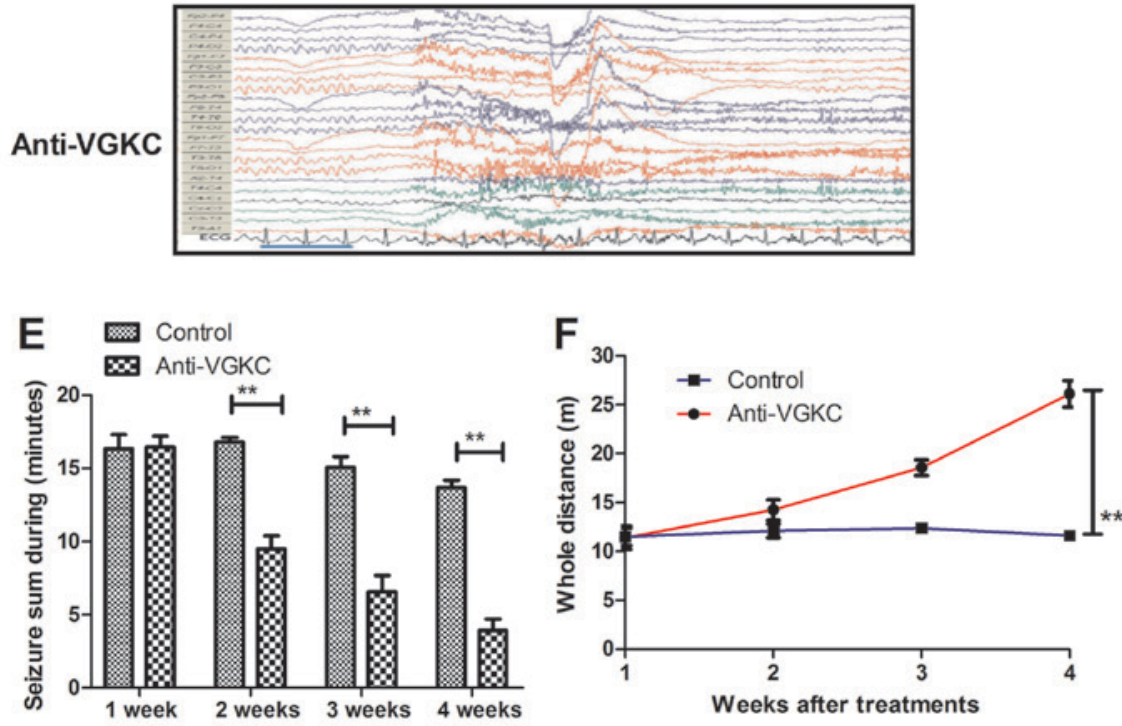

Figure 3. Relaxation effects of anti-VGKC on temporal lobe epileptiform spiking in mice with epilepsy. (A) Normalized spike rate plotted as a function of days of treatment with anti-VGKC or control. (B) Mice behaviors in the anti-VGKC and control groups were scored by STESS. (C) EEG differences were compared between the anti-VGKC and control mice following the 30-day treatment period. (D) Examples of time-frequency (Morlet wavelets) power spectra from representative epileptic mice in the anti-VGKC and control groups during the 30-day treatment period. Power scale (right y axis) refers to $\mu \mathrm{V}^{2} / \mathrm{Hz}$. (E) Total seizure duration in epileptic mice following treatment with anti-VGKC or control. (F) Whole traveled distance in the open field activity test. The whole traveled distance in the open field tests were different between the anti-VGKC and control groups. Data are presented as the mean \pm standard deviation ( $\mathrm{n}=4 / \mathrm{group}$ ) ${ }^{* *} \mathrm{P}<0.01$, as indicated. VGKC, voltage gated potassium channel complex; STESS, Status Epilepticus Severity Score.

beneficial on cortical epileptiform spiking and neuronal remission in vivo in mice model of epilepsy, interictal spike rate and neuronal remission were assessed in the presence of Anti-VGKC in epilepsy mice model. Our data in Fig. 4A presented that the Anti-VGKC improved pronounced epileptic phenotype by observation of water maze path efficiency data. 

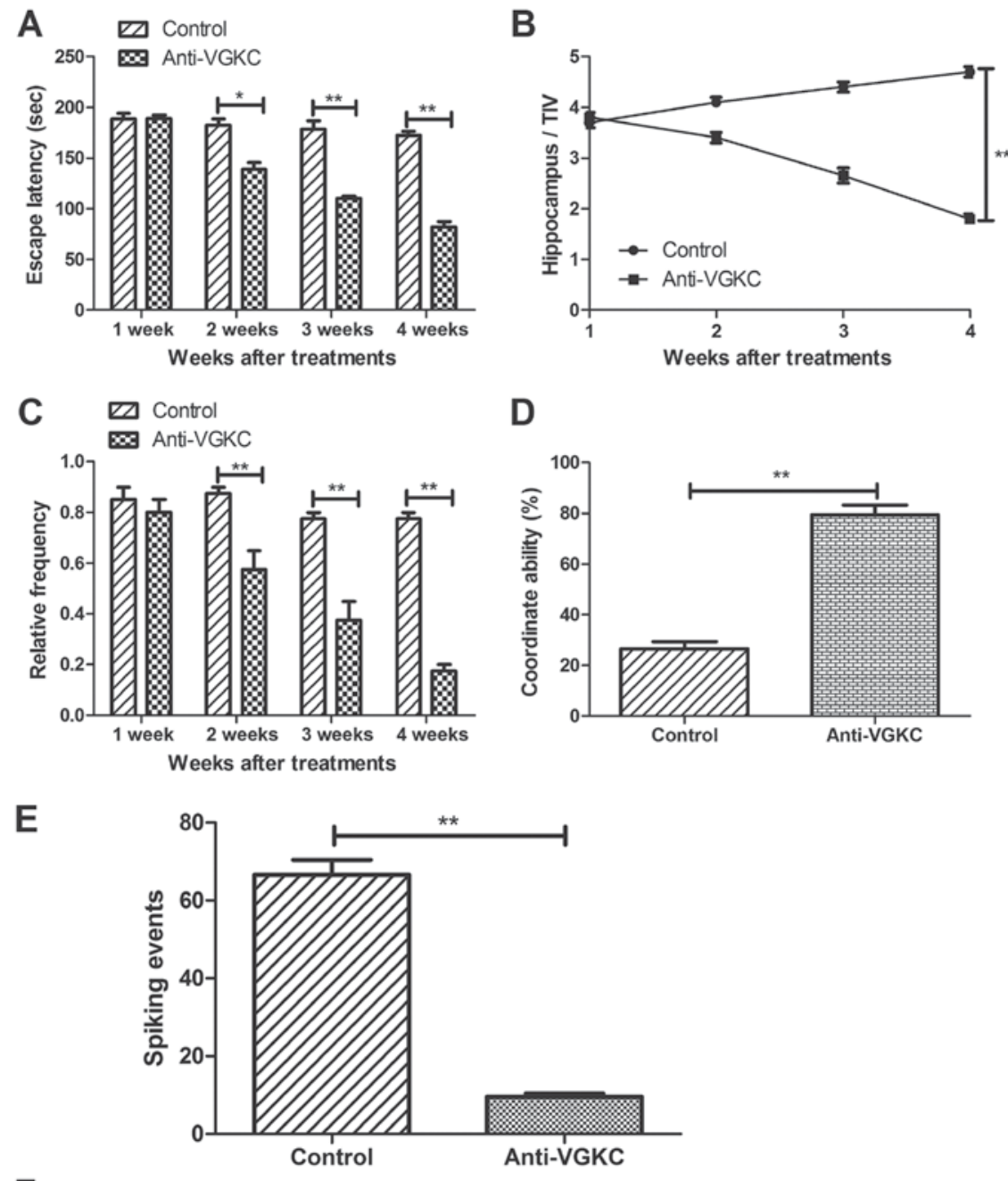

$\mathbf{F}$

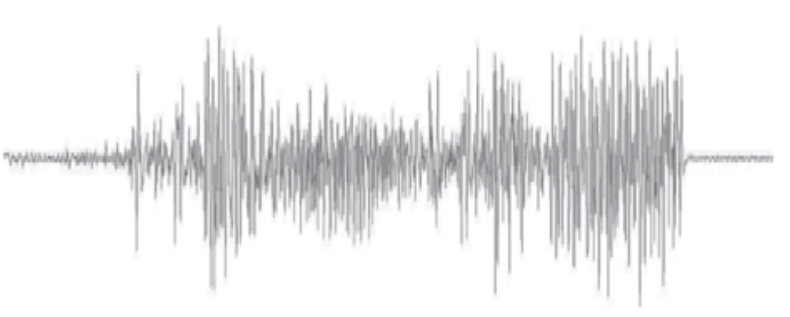

Anti-VGKC

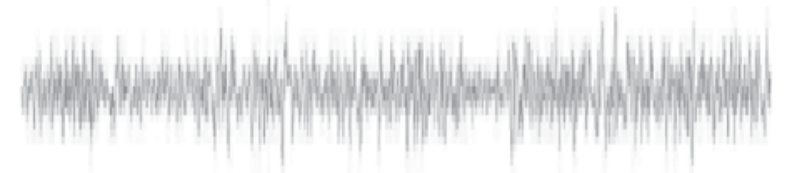

Figure 4. Improvement in the efficacy of anti-VGKC on behaviors for mice with epilepsy. (A) The Morris water maze test evaluated the escape latency between the anti-VGKC and control groups. (B) Volumetric hippocampal ratio of TIV between the anti-VGKC and control groups. (C) Seizure frequency in mice with epilepsy following treatment with anti-VGKC. (D) The coordinate abilities following the 30-day treatment period of anti-VGKC. (E) Spiking events of faciobrachial dystonic seizures in epileptic mice following anti-VGKC treatment (53\%) compared with the control group. (F) Representative electroencephalography in experimental mice in the hippocampus of anti-VGKC- or control-treated mice on day 30. Data are presented as the mean \pm standard deviation $\left(\mathrm{n}=4\right.$ /group). ${ }^{* *} \mathrm{P}<0.01$, as indicated. VGKC, voltage gated potassium channel complex; TIV, total intracranial volume.

Anti-VGKC treatment significantly reduced the spike discharge rate compared to control in mice with epilepsy (Fig. 4B, Bonferroni post-hoc, $\mathrm{P}<0.01)$. The frequency of seizures in mice treated with Anti-VGKC was significantly reduced from $1.46 \pm 0.35$ seizures for vehicle to $0.31 \pm 0.08$ seizures for Anti-VGKC ( $\mathrm{P}<0.01$, t-test, Fig. 4C). We also found that mice treated with Anti-VGKC exhibited significant difference in coordinating behavior and spiking frequency of hippocampus between Anti-VGKC and control group (Fig. 4D and E). Also, the results in Fig. $4 \mathrm{~F}$ indicated that the coordinate ability was significantly improved by Anti-VGKC compared to control (One-way ANOVA, $\mathrm{P}<0.01$ ). These data indicated that Anti-VGKC was beneficial for epileptiform spiking and neuronal remission in vivo in mice model of epilepsy. 
A
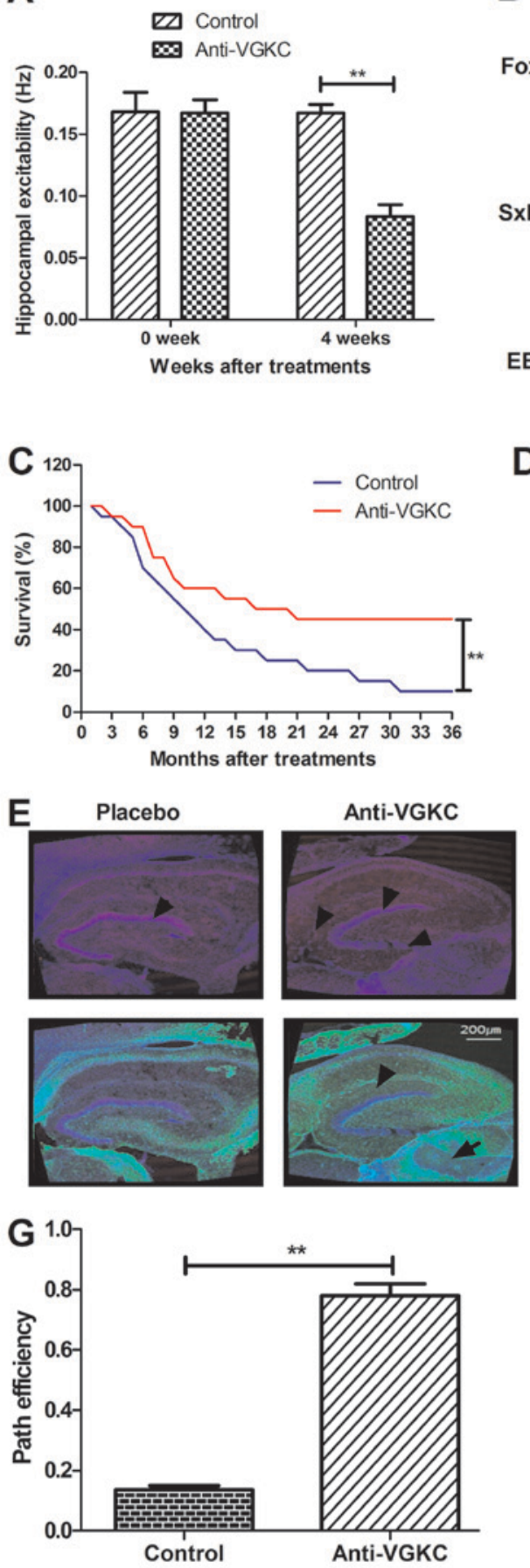

B
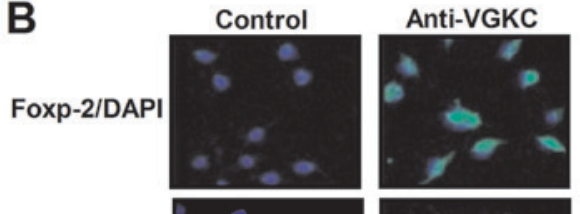

SxIP/DAPI
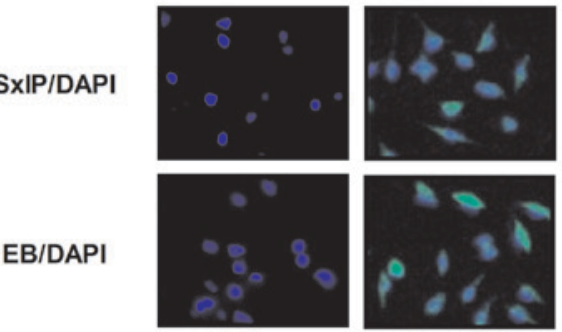

D

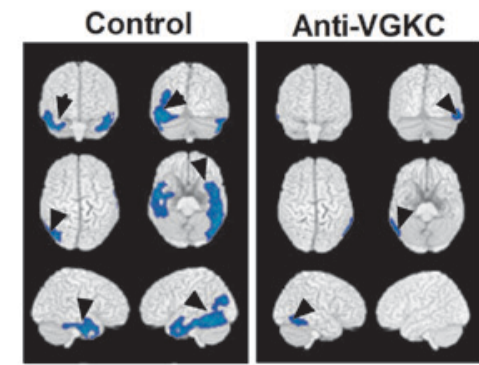

$\mathbf{F}$

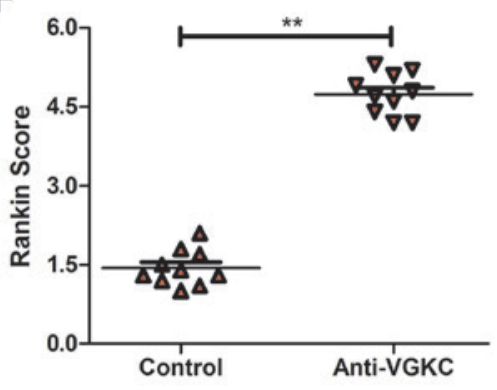

H

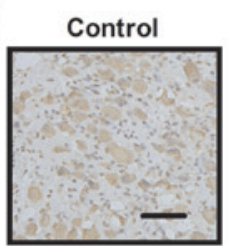

Anti-VGKC

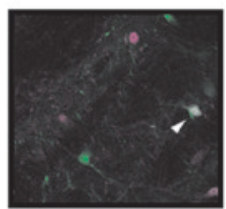

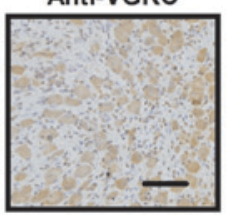

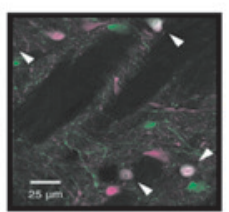

Figure 5. Target treatment of anti-VGKC on the hippocampus of mice with epilepsy. (A) Hippocampus excitability was downregulated following 4-week treatment with anti-VGKC compared with the control group. (B) Neuroprotective protein expression of Foxp-2, EB and SxIP were upregulated in hippocampus cells following anti-VGKC treatment in mice with epilepsy (magnification, x20). (C) Anti-VGKC treatment significantly improved the survival of epilepsy-bearing mice compared with the control group. (D) Discharge sites (indicated by arrows) were decreased in the temporal lobe following anti-VGKC treatment in vivo compared with the control group (magnification, x10). (E) Hippocampus treated with anti-VGKC showed dispersion of the pyramidal cell layer and more neurons by thionin staining (magnification, x20). (F) Anti-VGKC treatment significantly lowered prospective observation with epilepsy determined by Rankin score. (G) Anti-VGKC treatment significantly improved cognitive competence by Path efficiency measures. (H) Anti-VGKC treatment significantly improved the damaged neurons in the hippocampus analyzed by histology and immunofluorescence (magnification, $\mathrm{x} 20$ ). Data are presented as the mean \pm standard deviation ( $\mathrm{n}=6 /$ group. ${ }^{* *} \mathrm{P}<0.01$, as indicated. VGKC, voltage gated potassium channel complex; Foxp-2, forkhead-BOX P2; EB, microtubule end binding.

Anti-VGKC exhibits efficient effects on cognitive competence. To examine the efficacy of Anti-VGKC on network excitability, hippocampal slices from experimental mice were investigated in vitro. We demonstrated that Anti-VGKC treatment decreased the spike rate compared to control group (Fig. 5A). The immunohistochemical analysis of temporal lobe demonstrated that Foxp-2, SxIP and EB expression levels were up-regulated in brain in Anti-VGKC-treated mice (Fig. 5B). To investigate 
the long circulating carrier of Anti-VGKC, 36-month observation was conducted and survival rate was also recorded in this work. We showed that survival rate was relative higher in Anti-VGKC-treated mice with epilepsy as vehicle-treated as control (Fig. 5C). In addition, the discharge sites were analyzed by using FDG-PET at pre-surgery and post-surgery (Fig. 5D). Furthermore, thionin staining of hippocampi area in Anti-VGKC and control groups demonstrated significantly difference in dispersion of the pyramidal cell layer (Fig. 5E). At last, the cognitive competence and anxiety were evaluated after Anti-VGKC treatment in mice with epilepsy. As shown in Fig. 4F, results indicated Anti-VGKC treatment improved cognitive competences determined by Rankin score. We demonstrated that Anti-VGKC treatment significantly improved cognitive competence analyzing by path efficiency assay (Fig. 5F). Anti-VGKC treatment improved path efficiency of experimental mice compared to control (Fig. 5G). Anti-VGKC treatment also decreased the number of damaged neurons in hippocampus analyzed by histology and immunofluorescence (Fig. 5H). Taken together, the beneficial efficacy of Anti-VGKC showed significant and rapid effects on circuit excitability, neuroprotective protein and cognitive competences in vitro and in vivo, which also presented the action of Anti-VGKC for inhibition in neuronal hyperexcitability.

\section{Discussion}

Currently, drug therapies for preventing or treating epilepsy have been extensively used in clinic (34). Numerous factors contribute to the occurrence of epilepsy. As the worse environment pollution, more and more epilepsy patients occurred and appeared drug resistance (35). Therefore, comprehensive treatment for patients with epilepsy is critical in clinical therapy. This study demonstrates that the presence of Anti-VGKC $(0.24 \mathrm{mg})$ showed an efficient therapeutic approach in epileptic mice by intravenous injection, which is consistent with previous clinical reports and demonstrates better curative effects $(20,36)$. In addition, target therapy and immunotherapy of Anti-VGKC are more compatible used in treatment of patients with epilepsy more than other antiepileptic drugs that show more efficient for patients with epilepsy $(22,35,37)$. The present study showed that mice with epilepsy treatment with Anti-VGKC led to the therapeutic effects in preventing cognitive impairment and decreasing of neuronal loss in hippocampus. Furthermore, in this study, we not only demonstrated the impact of antiepileptic drug of Anti-VGKC on the efficacy and safety, but also provided a therapeutic schedule for clinic treatment of epilepsy. These are consistent intellectual efficacy, which have VGKC excessive expression in patients with epilepsy (38).

Previous study has reported that VGKC-complex antibodies were presented in patients with peripheral nerve Morvan's syndrome, hyperexcitability, epilepsy and limbic encephalitis $(18,39)$. Although Radja et al $(37)$ has showed that limbic encephalitis is usually caused by autoimmune neuropsychiatric condition. In particular, published study has also reported variable responses to immunosuppressive therapy in VGKC-complex antibody and their results that suggested VGKC-complex antibody showed significant improvements of epilepsy (37).
Here, our study found that the most significant improvements of Anti-VGKC treatment were demonstrated by epileptic mice presenting with cognitive impairment, neuron increasing and consistent neuroradiological changes. These observations illustrated the importance of Anti-VGKC for seizures frequency and improved epileptic phenomena in a 30-day treatment period. In addition, the inhibitory activity for hyperexcitability of neuron in mice model of epilepsy has not well understood $(40,41)$. This study clarified that hyperexcitability of neuron was aberrant. Furthermore, recent evidences in published studies have identified an essential role for impaired cortical interneurons and seizure localization of epilepsy was authenticated in mice model of epilepsy (42-44). Localization-related epilepsy was presumed to occur in a discrete cortical area in brain. Though identify the localization-related epilepsy is slight significance for control of seizures by epilepsy surgical operation, it was essential for doctors and clinicians in research and development of drug target therapy $(45,46)$. In this study, we have investigated the localization-related epilepsy in mice model of J20 and evaluated the efficacy of Anti-VGKC. We also indicated that discharge sites in hippocampus was related the seizures frequency.

Currently, response-element binding protein-dependent genes expression is significant difference between in temporal lobe epileptic mice hippocampus and healthy mice (47). Foxp-2, SxIP and EB expression levels that owned neuroprotection has investigated and showed a decreasing trend in mice with epilepsy in previous study $(48,49)$. In addition, a study has showed that the NAP (NAPVSIPQ) sequence of activity-dependent neuroprotective protein (ADNP) contains the SxIP motif, EB protein target, which is critical for microtubule dynamics leading to synaptic plasticity and neuroprotection in a schizophrenia mouse model (30). In this work, our design investigated Foxp-2, SxIP and EB expression levels prior and post treatment of Anti-VGKC. Though basal mRNA and protein owned neuroprotective protein are surprisingly frequently observed in epileptic mice, the changes of these neuroprotective protein did not studied in temporal lobe epilepsy of mice (50). Importantly, we studied changes of Foxp-2, SxIP and EB expression levels that owned neuroprotection in epileptic mice prior and post treatment with Anti-VGKC. These neuroprotective protein affected seizure frequency, cognitive impairment, anxiety and EEG observed in the most of events (51). These observations were most consistent with hippocampus seizure involvement and EEG. Interestingly, Anti-VGKC was not only significantly relieved hippocampus excitability and prolonged survival of epilepsy-bearing mice, but also presents a potential anti-epilepsy efficacy in path efficiency (52). Our data confirmed these therapeutic effects of Anti-VGKC in epilepsy mice.

In conclusion, the finding in the present study demonstrated that Anti-VGKC treatment not only improved cognitive impairment, but also repaired impaired neurons. We further investigated VGKC expression in serum and CSF. We showed that improvement of cognitive effects on mice with a model of intractable epilepsy after Anti-VGKC treatment. However, significant survival period, cognitive and behavior improvements were shown, which are major indexes for mice with intractable epilepsy. It is therefore important that plerosis of injured midbrain neuron, cognitive impairment, decreasing of 
seizures of Anti-VGKC, are investigated so that more trails upon Anti-VGKC treatments should be explore to explain mechanism of these observations.

\section{Acknowledgements}

Not applicable.

\section{Funding}

No funding was received.

\section{Availability of data and materials}

The analysed data sets generated during the study are available from the corresponding author on reasonable request.

\section{Authors' contributions}

SY designed the present study. ZIF and XF performed the experiments, and $\mathrm{ZgF}$ and $\mathrm{XZ}$ analysed the experimental data. The final version of the manuscript was read and approved by all authors.

\section{Ethics approval and consent to participate}

The present study was approved by the Ethics Committee of Provincial Hospital Affiliated to Shandong University (Shandong, China; ref. 11/H1011/102).

\section{Consent for publication}

Not applicable.

\section{Competing interests}

The authors declare that they have no competing interests.

\section{References}

1. Allers K, Essue BM, Hackett ML, Muhunthan J, Anderson CS, Pickles K, Scheibe F and Jan S: The economic impact of epilepsy: A systematic review. BMC Neurol 15: 245, 2015.

2. Sauro KM, Wiebe S, Dunkley C, Janszky J, Kumlien E, Moshé S, Nakasato N, Pedley TA, Perucca E, Senties H, et al: The current state of epilepsy guidelines: A systematic review. Epilepsia 57: 13-23, 2016.

3. Rathore C and Paterson R: Stopping antiepileptic drugs in patients with epilepsy in remission: Why, when and how? Neurol India 62: 3-8, 2014.

4. Markoula S, Teotonio R, Ratnaraj N, Duncan JS, Sander JW and Patsalos PN: Lacosamide serum concentrations in adult patients with epilepsy: The influence of gender, age, dose, and concomitant antiepileptic drugs. Ther Drug Monit 36: 494-498, 2014.

5. Braun KP and Schmidt D: Stopping antiepileptic drugs in seizure-free patients. Curr Opin Neurol 27: 219-226, 2014.

6. Stewart E, Catroppa C and Lah S: Theory of mind in patients with epilepsy: A systematic review and meta-analysis. Neuropsychol Rev 26: 3-24, 2016.

7. Wang J, Xing DG, Ma EM, Qiu B, Ou SW and Wang YJ: Microsurgical outcomes of secondary epilepsy from hippocampal lesions: A report of 56 cases and literature review. Turk Neurosurg 26: 29-38, 2016.

8. Verrotti A, Matricardi S, Rinaldi VE, Prezioso G and Coppola G: Neuropsychological impairment in childhood absence epilepsy: Review of the literature. J Neurol Sci 359: 59-66, 2015.
9. Buckmaster PS and Haney MM: Factors affecting outcomes of pilocarpine treatment in a mouse model of temporal lobe epilepsy. Epilepsy Res 102: 153-159, 2012.

10. Sanabria-Castro A, Henriquez-Varela F, Lara-Maier S, Monge-Bonilla C and Sittenfeld-Appel M: Characteristics of patients with refractory epilepsy attended in a tertiary referral center in Costa Rica. Rev Neurol 63: 58-64, 2016 (In Spanish).

11. Horvath GA, Demos M, Shyr C, Matthews A, Zhang L, Race S, Stockler-Ipsiroglu S, Van Allen MI, Mancarci O, Toker L, et al: Secondary neurotransmitter deficiencies in epilepsy caused by voltage-gated sodium channelopathies: A potential treatment target? Mol Genet Metab 117: 42-48, 2016.

12. Shen Y, Liao Y, Feng G, Gu X and Wan S: Uterine artery embolization for hemorrhage resulting from second-trimester abortion in women with scarred uterus: Report of two cases. Int J Clin Exp Med 8: 14196-14202, 2015.

13. Liu J, Liu Z, Ding H and Yang X: Adherence to treatment and influencing factors in a sample of Chinese epilepsy patients. Epileptic Disord 15: 289-294, 2013.

14. Möttönen T, Katisko J, Haapasalo J, Tähtinen T, Saastamoinen A, Peltola J, Öhman J and Lehtimäki K: The correlation between intraoperative microelectrode recording and 3-Tesla MRI in patients undergoing ANT-DBS for refractory epilepsy. Stereotact Funct Neurosurg 94: 86-92, 2016.

15. Lambrechts DA, Brandt-Wouters E, Verschuure P, Vles HS and Majoie MJ: A prospective study on changes in blood levels of cholecystokinin-8 and leptin in patients with refractory epilepsy treated with the ketogenic diet. Epilepsy Res 127: 87-92, 2016.

16. Xu YX, Wang HQ, Yan J, Sun XB, Guo JC and Zhu CQ: Antibody binding to cell surface amyloid precursor protein induces neuronal injury by deregulating the phosphorylation of focal adhesion signaling related proteins. Neurosci Lett 465: 276-281, 2009.

17. Bès C, Troadec S, Chentouf M, Breton H, Lajoix AD, Heitz F, Gross R, Plückthun A and Chardès T: PIN-bodies: A new class of antibody-like proteins with CD4 specificity derived from the protein inhibitor of neuronal nitric oxide synthase. Biochem Biophys Res Commun 343: 334-344, 2006.

18. Liimatainen S, Peltola J, Hietaharju A, Sabater L and Lang B: Lack of antibodies to NMDAR or VGKC-complex in GAD and cardiolipin antibody-positive refractory epilepsy. Epilepsy Res 108: 592-596, 2014

19. Watanabe O: Voltage-gated potassium channel-complex antibodies associated encephalopathy and related diseases. Brain Nerve 68: 1011-1023, 2016 (In Japanese).

20. Lilleker JB, Jones MS and Mohanraj R: VGKC complex antibodies in epilepsy: Diagnostic yield and therapeutic implications. Seizure 22: 776-779, 2013.

21. van Elst LT, Klöppel S and Rauer S: Voltage-gated potassium channel/LGI1 antibody-associated encephalopathy may cause brief psychotic disorder. J Clin Psychiatry 72: 722-723, 2011.

22. Lang B, Makuch M, Moloney T, Dettmann I, Mindorf S, Probst C, Stoecker W, Buckley C, Newton CR, Leite MI, et al: Intracellular and non-neuronal targets of voltage-gated potassium channel complex antibodies. J Neurol Neurosurg Psychiatry 88: 353-361, 2017.

23. Somers KJ and Sola CL: Voltage-gated potassium channel-complex antibody-associated limbic encephalitis. Psychosomatics 52: 78-81, 2011.

24. Aradillas E and Schwartzman RJ: Kinesigenic dyskinesia in a case of voltage-gated potassium channel-complex protein antibody encephalitis. Arch Neurol 68: 529-532, 2011.

25. Irani SR, Stagg CJ, Schott JM, Rosenthal CR, Schneider SA, Pettingill P, Pettingill R, Waters P, Thomas A, Voets NL, et al: Faciobrachial dystonic seizures: The influence of immunotherapy on seizure control and prevention of cognitive impairment in a broadening phenotype. Brain 136: 3151-3162, 2013.

26. González Otárula KA, Ugarnes G, Fernández Suárez M and D'Giano C: Faciobrachial dystonic seizures. Semiologic diagnosis in limbic encephalitis. Medicina (B Aires) 75: 407-409, 2015 (In Spanish).

27. Livak KJ and Schmittgen TD: Analysis of relative gene expression data using real-time quantitative PCR and the 2(-Delta Delta C(T)) method. Methods 25: 402-408, 2001

28. Teoh EJ, McGowan DR, Bradley KM, Belcher E, Black E, Moore A, Sykes A and Gleeson FV: 18F-FDG PET/CT assessment of histopathologically confirmed mediastinal lymph nodes in non-small cell lung cancer using a penalised likelihood reconstruction. Eur Radiol 26: 4098-4106, 2016. 
29. Bharmal AV, Kent BA, Bussey TJ and Saksida LM: Performance of transgenic TgTau-P301L mice in a 5-choice serial reaction time task (5-CSRTT) as a model of Alzheimer's disease. Psychiatr Danub 27 (Suppl 1): S515-S525, 2015.

30. Vaisburd S, Shemer Z, Yeheskel A, Giladi E and Gozes I: Risperidone and NAP protect cognition and normalize gene expression in a schizophrenia mouse model. Sci Rep 5: 16300 , 2015.

31. Dennis M, Mead G, Doubal F and Graham C: Determining the modified Rankin score after stroke by postal and telephone questionnaires. Stroke 43: 851-853, 2012.

32. Rossetti AO, Logroscino G, Milligan TA, Michaelides C, Ruffieux C and Bromfield EB: Status epilepticus severity score (STESS): A tool to orient early treatment strategy. J Neurol 255: $1561-1566,2008$

33. Khodaie B, Lotfinia AA, Ahmadi M, Lotfinia M, Jafarian M, Karimzadeh F, Coulon P and Gorji A: Structural and functional effects of social isolation on the hippocampus of rats with traumatic brain injury. Behav Brain Res 278: 55-65, 2015.

34. Arida RM, de Almeida AC, Cavalheiro EA and Scorza FA: Experimental and clinical findings from physical exercise as complementary therapy for epilepsy. Epilepsy Behav 26 273-278, 2013.

35. Sandow N, Kim S, Raue C, Päsler D, Klaft ZJ, Antonio LL, Hollnagel JO, Kovacs R, Kann O, Horn P, et al: Drug resistance in cortical and hippocampal slices from resected tissue of epilepsy patients: No significant impact of p-glycoprotein and multidrug resistance-associated proteins. Front Neurol 6: 30, 2015.

36. Huda S, Wong SH, Pettingill P, O'Connell D, Vincent A and Steiger M: An 11-year retrospective experience of antibodies against the voltage-gated potassium channel (VGKC) complex from a tertiary neurological centre. J Neurol 262: 418-424, 2015.

37. Radja GK and Cavanna AE: Treatment of VGKC complex antibody-associated limbic encephalitis: A systematic review. J Neuropsychiatry Clin Neurosci 25: 264-271, 2013.

38. Park SB: The clinical relevance of voltage gated potassium channel (VGKC)-complex antibodies: The story is still unfolding. J Neurol Neurosurg Psychiatry 85: 596, 2014.

39. Watanabe O: Anti-VGKC complex antibody associated limbic encephalitis. Nihon Rinsho 73 (Suppl 7): S613-S618, 2015 (In Japanese).

40. Menon P, Kiernan MC and Vucic S: Cortical hyperexcitability precedes lower motor neuron dysfunction in ALS. Clin Neurophysiol 126: 803-809, 2015.

41. Nuwer MO, Picchione KE and Bhattacharjee A: PKA-induced internalization of slack $\mathrm{KNa}$ channels produces dorsal root ganglion neuron hyperexcitability. J Neurosci 30: 14165-14172, 2010 .
42. Sotgiu ML and Biella G: Differential effects of MK-801, a $\mathrm{N}$-methyl-D-aspartate non-competitive antagonist, on the dorsal horn neuron hyperactivity and hyperexcitability in neuropathic rats. Neurosci Lett 283: 153-156, 2000.

43. Murro AM, Park YD, King DW, Gallagher BB, Smith JR, Yaghmai F, Toro V, Figueroa RE, Loring DW and Littleton W: Seizure localization in temporal lobe epilepsy: A comparison of scalp-sphenoidal EEG and volumetric MRI. Neurology 43: 2531-2533, 1993.

44. Englot DJ, Nagarajan SS, Imber BS, Raygor KP, Honma SM, Mizuiri D, Mantle M, Knowlton RC, Kirsch HE and Chang EF: Epileptogenic zone localization using magnetoencephalography predicts seizure freedom in epilepsy surgery. Epilepsia 56: 949-958, 2015.

45. Marson AG, Hutton JL, Leach JP, Castillo S, Schmidt D, White S, Chaisewikul R, Privitera M and Chadwick DW: Levetiracetam, oxcarbazepine, remacemide and zonisamide for drug resistant localization-related epilepsy: A systematic review. Epilepsy Res 46: 259-270, 2001

46. Chaisewikul R, Privitera MD, Hutton JL and Marson AG: Levetiracetam add-on for drug-resistant localization related (partial) epilepsy. Cochrane Database Syst Rev: CD001901,2001.

47. Dubey D and Porter BE: CRTC1 nuclear localization in the hippocampus of the pilocarpine-induced status epilepticus model of temporal lobe epilepsy. Neuroscience 320: 57-68, 2016.

48. Bourque M, Morissette M and Di Paolo T: Neuroprotection in Parkinsonian-treated mice via estrogen receptor $\alpha$ activation requires $\mathrm{G}$ protein-coupled estrogen receptor 1 . Neuropharmacology 95: 343-352, 2015.

49. Loebel A and Citrome L: Lurasidone: A novel antipsychotic agent for the treatment of schizophrenia and bipolar depression. BJPsych Bull 39: 237-241, 2015.

50. Loebel A, Brams M, Goldman RS, Silva R, Hernandez D, Deng L, Mankoski R and Findling RL: Lurasidone for the treatment of irritability associated with autistic disorder. J Autism Dev Disord 46: 1153-1163, 2016.

51. Calabrese J, Rajagopalan K, Ng-Mak D, Bacci ED, Wyrwich K, Pikalov A and Loebel A: Effect of lurasidone on meaningful change in health-related quality of life in patients with bipolar depression. Int Clin Psychopharmacol 31: 147-154, 2016.

52. Enomoto T, Ishibashi T, Tokuda K, Ishiyama T, Toma S and Ito A: Lurasidone reverses MK-801-induced impairment of learning and memory in the Morris water maze and radial-arm maze tests in rats. Behav Brain Res 186: 197-207, 2008.

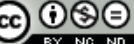

This work is licensed under a Creative Commons Attribution-NonCommercial-NoDerivatives 4.0 International (CC BY-NC-ND 4.0) License. 